M. Abedrabbo, W. Leterme and D. Van Hertem, "Analysis and enhanced topologies of active-resonance DC circuit breaker," 9th European Conference on Power Electronics (EPE'17 ECCE Europe), Warsaw, Poland, Sept. 11-14, 2017, 10 pages.

Digital Object Identifier: 10.23919/EPE17ECCEEurope.2017.8099371

URL (IEEE Xplore Digital Library):

http://ieeexplore.ieee.org/document/8099371/

(C) 2017 EPE and IEEE. This paper is a postprint of a paper submitted to and accepted for publication in Proc. 19 ${ }^{\text {th }}$ European Conference on Power Electronics and Applications (EPE'17 ECCE Europe) and is subject to European Power Electronics and Drives Association and IEEE Copyright. The copy of record is available at IEEE Xplore Digital Library. 


\title{
Analysis and Enhanced Topologies of Active-Resonance DC Circuit Breaker
}

\author{
Mudar Abedrabbo, Willem Leterme and Dirk Van Hertem \\ Dept. Electrical Engineering, K.U. Leuven ${ }^{(1)} /$ EnergyVille $^{(2)}$ \\ ${ }^{(1)}$ Kasteelpark Arenberg 10 (PB2445)/ ${ }^{(2)}$ Thor Park 8310 \\ ${ }^{(1)}$ Leuven/ ${ }^{(2)}$ Genk, Belgium \\ Phone: +32 (16) 321147 \\ Fax: +32 (16) 321985 \\ Email: mudar.abedrabbo@kuleuven.be \\ (1)URL: http://www.esat.kuleuven.be/electa \\ ${ }^{(2)}$ URL: http://www.energyville.be/en
}

\section{Keywords}

$\ll \mathrm{HVDC} \gg, \ll \mathrm{DC}$ circuit breaker $\gg, \ll$ Active-resonance DC circuit breaker $\gg$.

\begin{abstract}
DC circuit breakers are needed in future HVDC grids to provide selectivity in clearing DC faults and to achieve continuous operation of the healthy part of the grid. Standard mechanical circuit breakers as used in AC systems cannot be used in HVDC applications due to the lack of current zero-crossing, which is essential for arc extinction. To use mechanical interrupters for fault current interruption in DC applications, resonant circuits are used to create artificial current zero-crossings, by superimposing the resonant current on the DC current in the circuit breaker. Although the resonant current creates the zero-crossing, it introduces stresses on the mechanical circuit breaker and limits its rating, since the superimposed resonant current possibly introduces large peaks before current interruption.

This paper proposes an improved active-resonance DC circuit breaker topology which aims to increase breaker ratings by avoiding these peaks. The improved topology is able to control the direction of resonant current injection, limit internal circuit breaker currents and allows for multiple interruption attempts. The principle of operation and advantages over presently proposed topologies have been verified by simulation results.
\end{abstract}

\section{Introduction}

The interest in the multi-terminal HVDC grid increases rapidly, since it is considered as a promising solution for high power transmission over long distances and interconnecting asynchronous AC grids, especially in systems with high penetration of renewable energy sources. However, protection of the HVDC grid represents one of the main technical challenges. To build a multi-terminal HVDC grid, a reliable protection system and fast, economic DC circuit breakers are seen as indispensable components [1]. To achieve a selective protection and to assure the continuous operation of the grid, DC circuit breakers are needed.

The DC circuit breakers can be classified into three main categories. The solid-state DC circuit breaker represents the first category which consists of series-connected power electronic switches in parallel with energy absorption devices as shown in Fig. 1(a) [2]. Although the semiconductor devices provide arcless fast switching and meet the requirement of the HVDC grid with respect to interruption time, the on-state losses of this circuit breaker, which can reach up to 30\% of the VSC converter station losses [3], are considered to be the main drawback of this type. Therefore, the other two categories, hybrid and mechanical DC circuit breakers, are more appropriate for HVDC grid applications. 
The hybrid circuit breaker consists of a solid-state circuit breaker and a mechanical disconnector as illustrated in Fig. 1(b). The current flows through two or more low voltage power electronic devices (IGBTs) in series with the mechanical disconnector during normal operation. However, the current commutates to the solid-state circuit breaker during the interruption process [4]. Similar to the solidstate type, the power electronic switches in the main path of the current makes the hybrid circuit breaker suffering from on-state losses. However, the losses of the hybrid circuit breaker are much lower compared to the solid-state type [2].

The mechanical DC circuit breaker has a pure mechanical interrupter in the normal operation path, which makes it superior among the solid-state and hybrid circuit breakers in terms of on-state losses. The mechanical DC circuit breakers consist of three parallel connections: the mechanical interrupter (normal operation path), the current commutation circuit, which is necessary to create an artificial zero-crossing through the mechanical interrupter, and the energy absorption (Fig. 1(c)).

Various mechanical circuit breakers have been proposed for high-power applications depending on the commutation circuit types. In [5], a pulse generator composed of capacitor, inductor and thyristor, is used to create the current zero-crossing. Whereas in [6], a capacitor with IGBT switches are used to generate a pulsed current to bring the fault current to zero in the mechanical interrupter.

A passive commutation method, as proposed in [7], utilizes a passive resonant circuit to form the current zero-crossing. In [8], a low-voltage power electronic converter connected in series with the passive resonant circuit is used to improve the excitation process of the resonant current. While a pre-charged capacitor is connected in series with an inductor to form an active resonant circuit has been proposed in [9].

The goal of this paper is to propose a new type of active-resonance DC breaker which improves the breaking capability of the mechanical interrupter in terms of limiting the superimposed current, controlling the resonant current injection direction and increasing the number of current zero-crossing points. The innovation consists of the development of a modified resonant circuit of the active-resonance DC circuit breaker. The paper will be organized as follows: the first section discusses the principle of operation of two types of DC mechanical circuit breakers. The drawbacks of the conventional topology of the active-resonance DC circuit breaker are discussed in the second section. In the third section, the principle of operation of the enhanced active-resonance DC circuit breaker topology is explained. In the last section, conclusions are drawn.

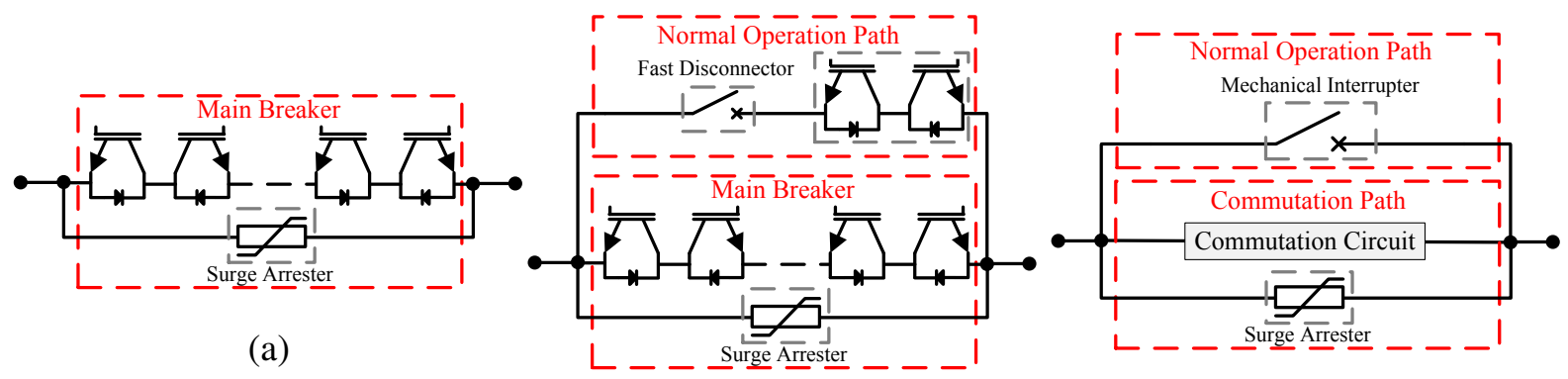

(b)

(c)

Fig. 1: (a) Solid-state DC circuit breaker, (b) Hybrid DC circuit breaker, (c) Mechanical DC circuit breaker.

\section{Principle of operation of mechanical DC circuit breakers}

\section{Passive-resonance circuit breaker}

The passive-resonance circuit breaker is able to interrupt the DC current by forming a current zerocrossing by superimposing the resonant current $i_{R e s}$ on the current in the mechanical interrupter $i_{B}$ (Fig. 2(a)). As soon as the contacts of the mechanical interrupter separate from each other, an electric arc is formed between them. The electric arc voltage triggers the resonant circuit, and a current with a resonant frequency is generated [10]. 


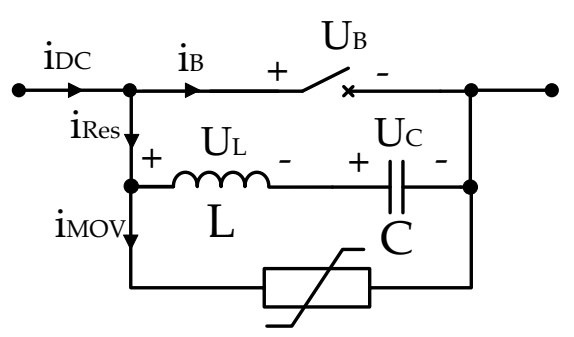

(a)

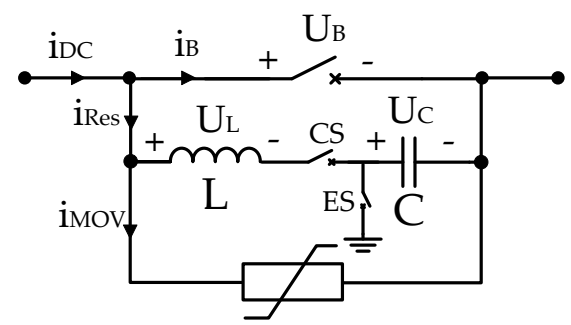

(b)

Fig. 2: (a) Passive-resonance DC circuit breaker, (b) Active-resonance DC circuit breaker.

Using Kirchhoff's voltage law (KVL) to the internal loop in Fig 2(a) (the mechanical interrupter and the resonant circuit during arcing process) [11], the arc voltage $\left(U_{B}\right)$ is given by (1). The arc voltage can be represented as a non-linear function of the arc current $\left(i_{B}\right)$ as described in (1) [10].

$$
U_{B}=f\left(i_{B}\right)=L \frac{d i_{R e s}}{d t}+\frac{1}{C} \int i_{R e s} d t
$$

By differentiating both sides of (1), (2) is derived, where $\frac{d U_{B}}{d i_{B}}$ is the resistance of the arc [10]. Due to the inductance of components in the grid, the rate of change of the DC current $\left(\frac{d i_{D C}}{d t}\right)$ is much less than the rate of change of the resonant current $\left(\frac{d i_{R e s}}{d t}\right)$. Hence, $\frac{d i_{D C}}{d t}$ can be negated from (2).

$$
\frac{d U_{B}}{d i_{B}} \frac{d i_{B}}{d t}=\frac{d U_{B}}{d i_{B}}\left(\frac{d i_{D C}}{d t}-\frac{d i_{\text {Res }}}{d t}\right)=L \frac{d^{2} i_{\text {Res }}}{d t^{2}}+\frac{1}{C} i_{\text {Res }}
$$

To generate an oscillatory behavior, the roots of (2) should be complex. Consequently the following condition should be satisfied: $-2 \sqrt{\frac{L}{C}}<\frac{d U_{B}}{d i_{B}}<2 \sqrt{\frac{L}{C}}$. Since the arc voltage is inversely proportional to the arc current [7], this condition is simplified to: $-2 \times \sqrt{\frac{L}{C}}<\frac{d U_{B}}{d i_{B}}<0$. Furthermore, the initial conditions at the instant of interruption are: $i_{R e s}(0)=0$ and $\frac{d i_{R e s}(0)}{d t}=\frac{U_{L}(0)}{L}=\frac{U_{B}(0)}{L}$.

By considering a vacuum interrupter as proposed in [12], the arc resistance is insignificant for high voltage applications [13]. Hence, the solution of (2) as shown in (3) [11] can be simplified as shown in (4).

$$
\begin{aligned}
& i_{\text {Res }}(t)=\frac{U_{B}(0)}{\omega L} e^{-\left(\frac{1}{2 L}\right)\left(\frac{d U_{B}}{d i_{B}}\right) t} \sin (\omega t), \text { where } \omega=\sqrt{\frac{1}{L C}-\left(\frac{1}{2 L} \frac{d U_{B}}{d i_{B}}\right)^{2}} \\
& i_{\text {Res }}(t) \approx \frac{U_{B}(0)}{\sqrt{\frac{L}{C}}} e^{-\left(\frac{1}{2 L}\right)\left(\frac{d U_{B}}{d i_{B}}\right) t} \sin (\omega t), \text { where } \omega \approx \frac{1}{\sqrt{L C}}
\end{aligned}
$$

Equation (4) shows that the current $i_{R e s}$ is proportional to the voltage of the arc $U_{B}(0)$. In case of high currents interruption, $U_{B}(0)$ will be very low (as the arc voltage is inversely proportional to the interrupted current). Accordingly, the magnitude of $\frac{d U_{B}}{d i_{B}}$ is low. Therefore, the term $\frac{U_{B}(0)}{\sqrt{\frac{L}{C}}} e^{-\left(\frac{1}{2 L}\right)\left(\frac{d U_{B}}{d i_{B}}\right) t}$ will have a low rate of rise leading to an increase in the time required of the resonant current to build up to the value of the DC current $\left(i_{D C}\right)$ to create the current zero-crossing. Furthermore, the larger $\frac{C}{L}$ results in larger current; however, the resonant frequency $\left(\omega \approx \frac{1}{\sqrt{L C}}\right)$ and $\frac{d i_{B}}{d t}$ are affected, which influence the breaking performance of the mechanical interrupter.

The dependency of the interruption process on the arc behavior in the mechanical interrupter leads to long interruption time which is considered as the main drawback of the passive-resonance DC circuit breaker. 


\section{Active-resonance circuit breaker}

To overcome the drawback associated with the passive-resonance DC circuit breaker, the active-resonance DC circuit breaker utilizes a pre-charged capacitor in the resonant circuit. The energy stored in this capacitor can be used to generate high peak currents during the interruption process.

In this type of circuit breaker a pre-charged capacitor is connected in series with a commutation switch in the resonant circuit (Fig. 2(b)). During normal operation, the commutation switch is off. When the resonant circuit needs to be excited throughout the breaking process, the commutation switch is closed. Closing the commutation switch releases the stored energy in the capacitor in the form of high resonant current. The capacitor $C$ in Fig. 2(b) can be charged by turning on the switch $E S$ and turning off the switch $C S$ during normal operation. However, $E S$ will be off and $C S$ will be fired at the instant of starting the breaking process.

By following the same analysis of the passive-resonance DC circuit breaker, the resonant current is derived in (5). Unlike the passive-resonance DC circuit breaker, the resonant current $i_{\text {Res }}$ and the initial voltage of the capacitor $U_{C}(0)$ are directly proportional.

$$
i_{\text {Res }}(t) \approx \frac{U_{B}(0)-U_{C}(0)}{\sqrt{\frac{L}{C}}} e^{-\left(\frac{1}{2 L}\right)\left(\frac{d U_{B}}{d i_{B}}\right) t} \sin (\omega t)
$$

\section{Drawbacks of active-resonance DC circuit breaker}

Fig. 3 shows the positive pole current in the mechanical interrupter $\left(i_{B}\right)$ of the conventional activeresonance DC circuit breaker for two cases: (a) the circuit breaker interrupts a positive DC current $\left(i_{D C}\right)$, (b) the circuit breaker interrupts a negative DC current. In case of high $d i_{B} / d t$ at current zero-crossing, current interruption may fail at the first zero-crossing. Therefore, to demonstrate the potential impact of failed interruption, it has been assumed that interruption occurs at the third current-zero crossing.

At $t=4 \mathrm{~ms}$, the resonant circuit is excited, and the resonant current $\left(i_{\text {Res }}\right)$ with $5 \mathrm{kHz}$ resonant frequency is superimposed on the DC current in the mechanical interrupter. The resonant current forces the positive DC current in the mechanical interrupter to zero directly after turning on the commutation switch $C S$ as shown in Fig. 3(a). In case of successful interruption at the third zero-crossing, it oscillates between $-8 k A$ and $18 k A$. On the contrary, in case (b) the mechanical interrupter current decreases to $-17 k A$ before increasing to zero as illustrated in Fig. 3(b). Furthermore, it oscillates between $-17 k A$ and $6 \mathrm{kA}$ in case of successful interruption at the third zero-crossing (Fig. 3(b)). This introduces stress on the mechanical interrupter during the interruption process, and limits the interruption capability of the circuit breaker.

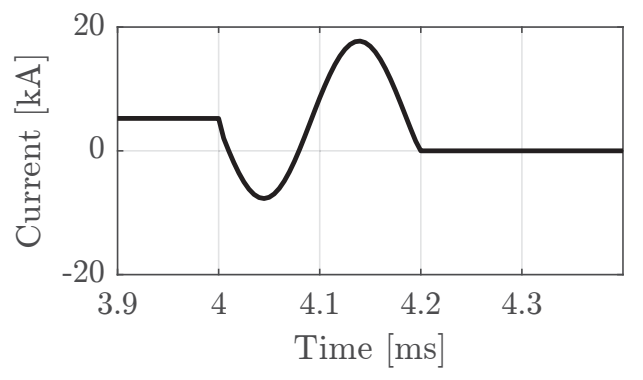

(a)

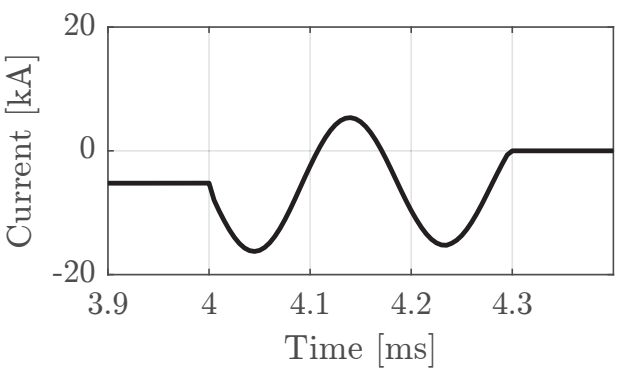

(b)

Fig. 3: The current in the mechanical interrupter $\left(i_{B}\right)$ of the conventional topology of the active-resonance DC circuit breaker during (a) positive DC current interruption, (b) negative DC current interruption.

The previously described interruption performance of the active-resonance DC circuit breaker is due to the fact that the topology shown in Fig. 2(b) can inject resonant current to the main path in one direction 
only, since the polarity of the capacitor cannot be reversed. Furthermore, this topology cannot limit the injected current in the mechanical interrupter path.

\section{Enhanced Active-Resonance DC circuit Breaker}

\section{Principle of operation}

To overcome the aforementioned problems, an H-bridge of thyristors is added to the resonant circuit as shown in Fig. 4. The improved topology has the advantage of directing the injected resonant current in both directions. Furthermore, it is able to limit the injected current in case of current interruption failure after the first zero-crossing to reduce the stress on the mechanical interrupter and to increase its interruption capability.

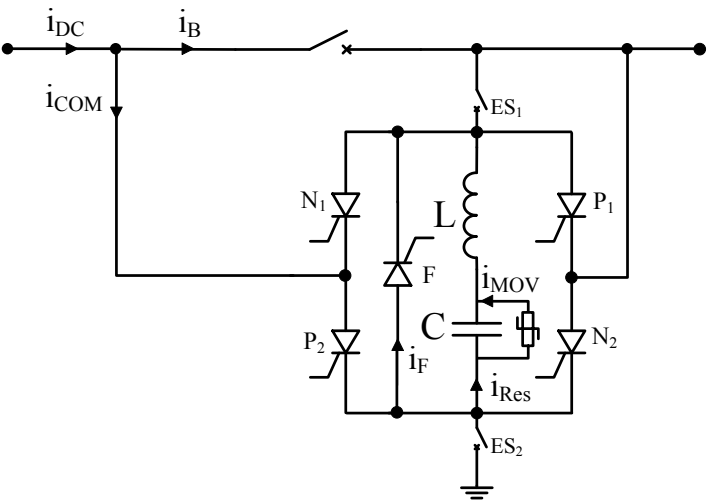

(a)

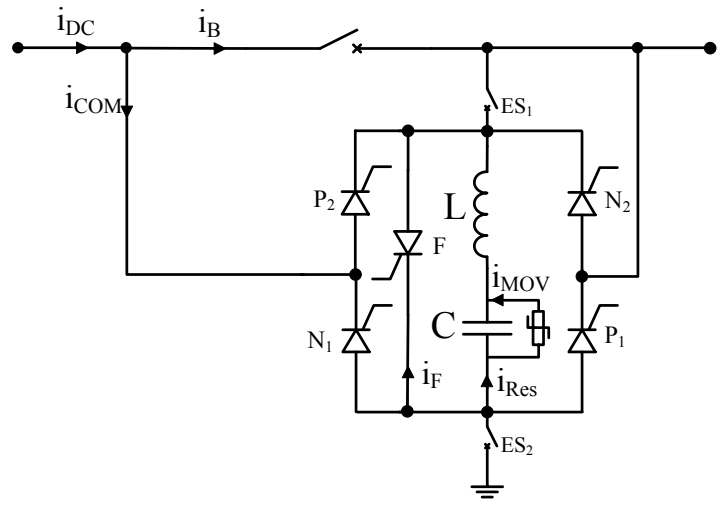

(b)

Fig. 4: Enhanced active-resonance DC circuit breaker for (a) positive pole, (b) negative pole.

To control the direction of the injected current according to the direction of the DC line current $\left(i_{D C}\right)$, thyristors $P_{1}$ and $P_{2}$ are fired when the DC line current is in the positive direction, whereas thyristors $N_{1}$ and $N_{2}$ are fired if the DC line current is in the negative direction. Furthermore, thyristor $F$ adds the ability of reversing the polarity of the capacitor $C$.

The symmetrical monopole point-to-point HVDC grid test system shown in Fig. 5 is used to demonstrate the principle of operation and the behavior of the proposed scheme. Half-bridge modular multilevel converters in this test system are modeled using the continuous MMC model presented in [14], and the PSCAD frequency dependent model of the cable is used. DC circuit breakers $\left(B_{12 p}, B_{12 n}, B_{21 p}\right.$ and $\left.B_{21 n}\right)$ are modeled as an ideal switch with delay of $4.2 \mathrm{~ms}$ in parallel with a thyristor H-bridge as proposed in Fig. 4. The resonant circuit is excited at $t=4 \mathrm{~ms}$; however, the ideal switch will open $0.2 \mathrm{~ms}$ after triggering the resonance to simulate the behavior of the mechanical interrupter within two zero-crossings of the resonant current. The parameters of the grid and the converters are listed in Table I.

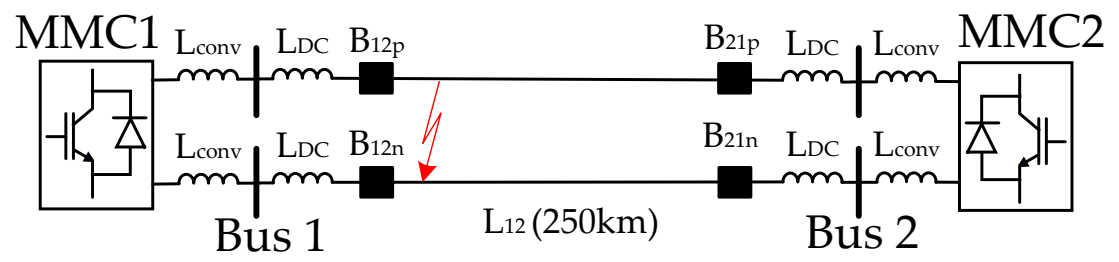

Fig. 5: Point-to-point HVDC grid test system.

A solid pole-to-pole fault is applied at the terminals of $L_{12}$ at $t=0 \mathrm{~ms}$, as shown in Fig. 5. The principle of operation and simulation results are discussed for breaker $B_{12 p}$ only.

Fig. 6 illustrates the different stages of the interruption process of the positive pole breaker $\left(B_{12 p}\right)$ with positive DC current when the breaker interrupts the current after the third zero-crossing. In simulation 
Table I: Parameters of HVDC grid test system based on [15].

\begin{tabular}{lcc}
\hline Parameters & MMC1 & MMC2 \\
\hline Operating mode & Rectifier & Inverter \\
Rated power [MVA] & 900 & 900 \\
DC voltage $[\mathrm{kV}]$ & 320 & 320 \\
AC grid voltage $[\mathrm{kV}]$ & 400 & 400 \\
Converter AC voltage $[\mathrm{kV}]$ & 380 & 380 \\
Transformer leakage reactance $[\mathrm{pu}]$ & $15 \%$ & $15 \%$ \\
Ac grid reactance $[\Omega]$ & 17.7 & 17.7 \\
Ac grid resistance $[\Omega]$ & 1.77 & 1.77 \\
Arm capacitance $[\mu F]$ & 29.3 & 29.3 \\
Arm reactor $[\mathrm{mH}]$ & 84.8 & 84.8 \\
Arm resistance $[\Omega]$ & 0.885 & 0.885 \\
Converter DC inductance $[\mathrm{mH}]$ & 10 & 10 \\
DC line inductance $[\mathrm{mH}]$ & 100 & 100 \\
\hline
\end{tabular}

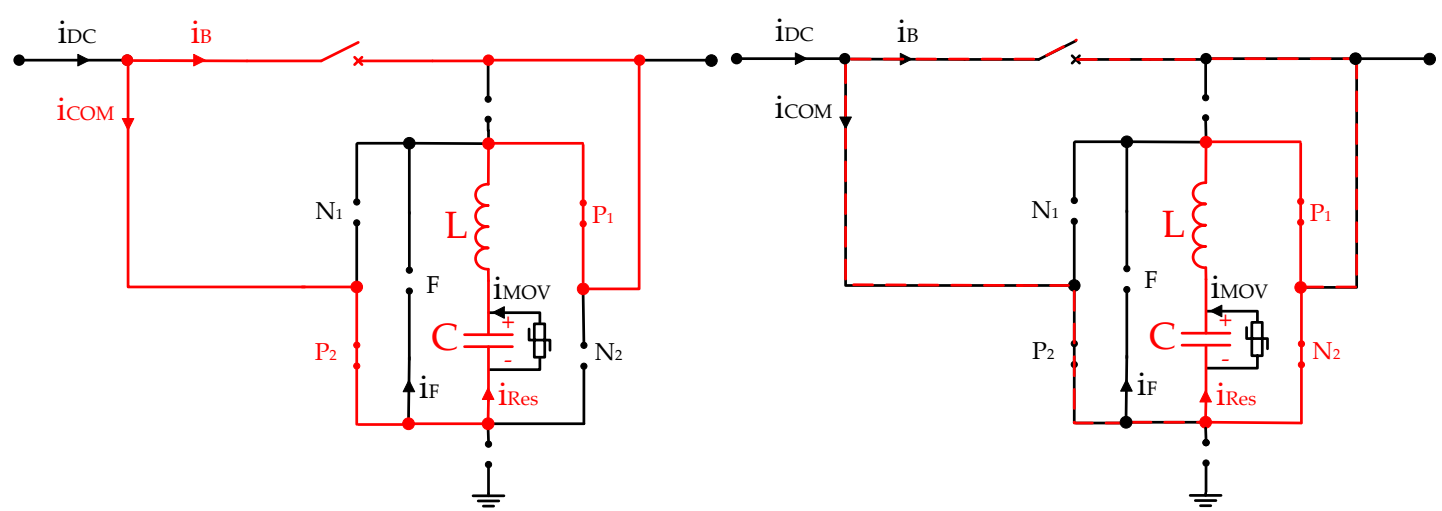

(a)

(b)

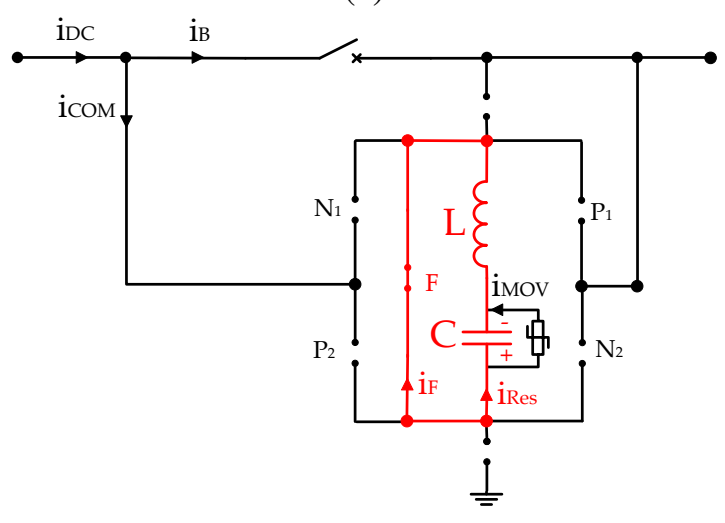

(c)

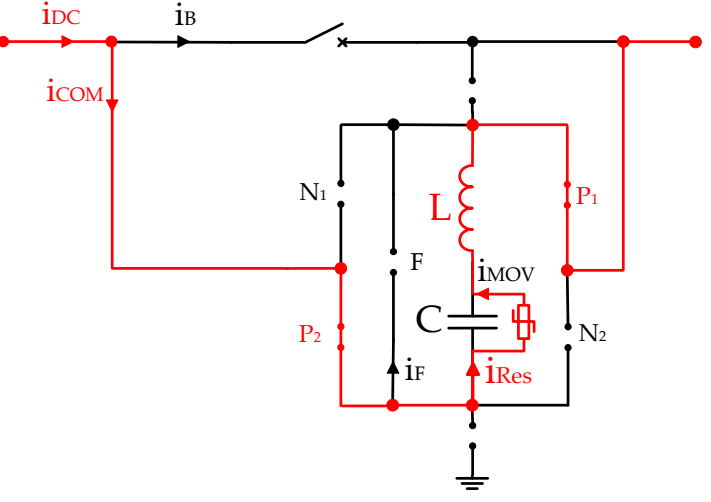

(d)

Fig. 6: Different stages of a positive DC current interruption process after several zero-crossings.

the switches $E S_{1}$ and $E S_{2}$ shown in Fig. 4 are turned on during normal operation. However, before the breaking process starts, both switches are turned off. The interruption process is described in four stages:

- Stage 1: $P_{1}$ and $P_{2}$ are turned on to trigger the resonance as shown in Fig. 6(a). The resonant current starts to increase in the opposite direction of the current in the mechanical interrupter as shown in the period $\Delta T_{1}$ in Fig. 7 (a) and (b). The current in the mechanical interrupter decreases 
during this stage as illustrated in Fig. 7(a). The current in the resonant circuit (solid black line) and the current in $P_{1}$ and $P_{2}$ (dashed green line) in Fig. 7(b) are equal.

- Stage 2: After the first zero-crossing of the breaker current (at the end of $\Delta T_{1}$ ), the mechanical interrupter fails to interrupt the current. Hence, $N_{2}$ is turned on, as illustrated in Fig. 6(b), to limit the current in the mechanical interrupter during the period $\Delta T_{2}$ (Fig. 7(a)). As demonstrated in Fig. 7(b) during $\Delta T_{2}$, part of the resonant current commutates to $N_{2}$. Therefore, the current in $N_{2}\left(i_{N 2}\right)$ increases and the current in $P_{2}\left(i_{P 2}\right)$ decreases. The value of $i_{N 2}$ depends on the resistance of the arc in the mechanical interrupter, which is considered in this paper to be zero.

- Stage 3: At the end of the second stage the voltage polarity of the capacitor is reversed as shown in Fig. 7(c). Therefore, $F$ is turned on to reverse the polarity of the capacitor as shown in Fig. 6(c). During this stage $\left(\Delta T_{3}\right)$, the current in the mechanical interrupter $i_{B}$ is equal to the current in the DC line $i_{D C}$ (no resonant current appears in $i_{B}$ waveform in Fig.7(a)). At the end of $\Delta T_{3}$, the capacitor voltage rises to the positive peak voltage (Fig. 7(c)).

- Stage 4: Once the polarity of the capacitor is reversed, $F$ turns off, and $P_{1}$ and $P_{2}$ are fired to repeat the process until the circuit breaker succeeds to interrupt the current after several zero-crossings as shown in Fig. 7 and Fig. 8. During this stage, the resonant current increases in the opposite direction of $i_{B}$ as described in stage 1 , until $i_{B}$ is equal to zero $\left(\Delta T_{4}\right.$ in Fig. 7(a) and (b)). Once the mechanical interrupter successfully interrupts the current, the DC line current commutates to the resonant circuit as shown in Fig. 8. As a result, the capacitor charges, and the capacitor voltage increases until it reaches the limiting voltage of the surge arrestor. Thereafter, the surge arrester conducts the current and dissipates the stored energy from the DC inductance, until $i_{D C}$ drops to zero (Fig. 8).

\section{Comparison with conventional topology}

The proposed topology limits the current in the mechanical interrupter which reduces the stress and increases the number of zero-crossings during one cycle of the resonant current. Furthermore, it has the ability to control the direction of the resonant current in order to achieve the current zero-crossing as soon as possible. These features are illustrated in Fig. 9 and Table II, which compare the results of the proposed topology with the conventional topology.

Table II: Proposed topology vs. conventional topology as shown in Fig. 9

\begin{tabular}{cccc}
\hline & Direction of $i_{D C}$ & Proposed & Conventional \\
\hline Min. of $i_{B}[\mathrm{kA}]$ & + & -1.5 & -7.7 \\
Max. of $i_{B}[\mathrm{kA}]$ & + & 5.2 & 17.7 \\
Min. of $i_{B}[\mathrm{kA}]$ & - & -5.2 & -16.3 \\
Max. of $i_{B}[\mathrm{kA}]$ & - & 4 & 5.4 \\
Zero-crossings within $200 \mu \mathrm{s}$ & $+/-$ & 5 & 3 \\
\hline
\end{tabular}

\section{Options to charge the capacitor}

In the topology proposed in Fig. 4, the capacitor can be charged by turning on $E S_{1}$ and $E S_{2}$ during normal operation. The resonant circuit is capable all the time to inject current in both directions depending on the direction of the DC current. Using $E S$ between the capacitor and inductor as shown in Fig. 10 instead of $E S_{1}$ and $E S_{2}$ in Fig. 4, the capacitor can be charged by turning on $E S$ and $P_{2}$ in case of the positive pole topology shown in Fig. 10(a). For the negative pole topology shown in Fig. 10(b), the capacitor can be charged by turning on $E S$ and $N_{1}$. The topologies in Fig. 10 require fewer switches compared to the topology in Fig. 4, however, before starting the interruption process, F should be turned on to reverse the polarity of the capacitor, afterwards, the current can be injected to the mechanical interrupter depending on the direction of the DC current. 


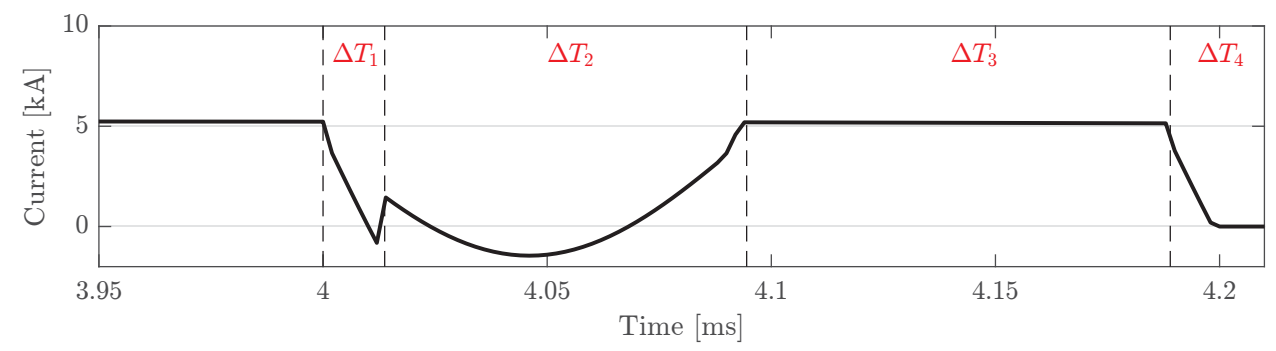

(a)

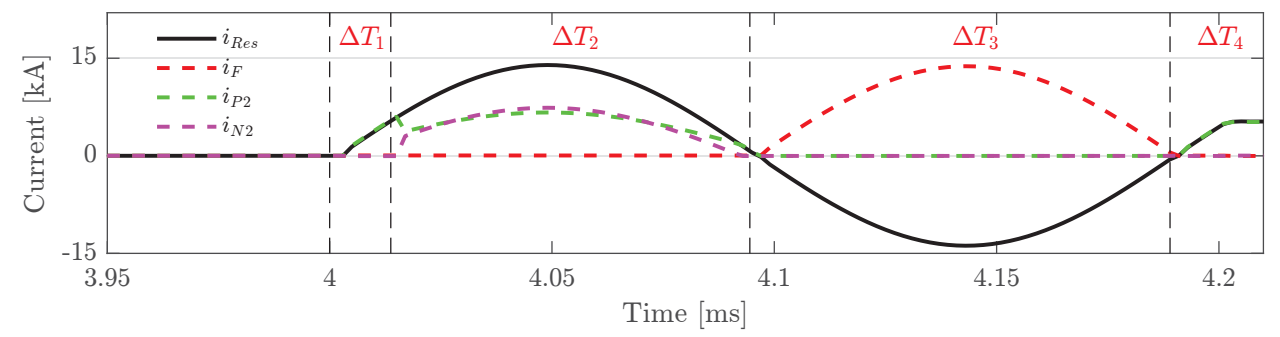

(b)

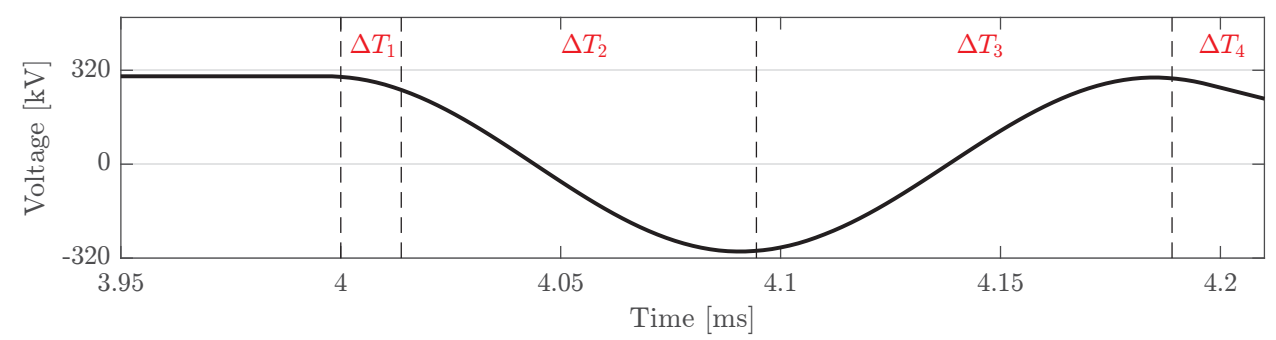

(c)

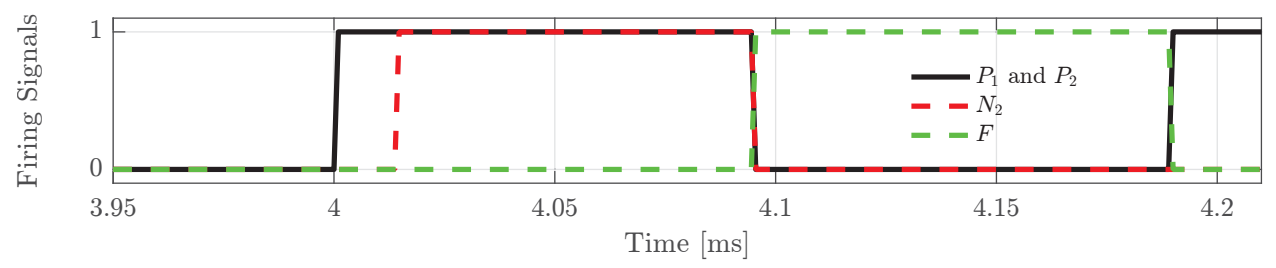

(d)

Fig. 7: Stages of a positive DC current interruption process (a) Mechanical interrupter current $i_{B}$, (b) resonant and thyristor currents, (c) capacitor voltage, (d) thyristor firing signals.

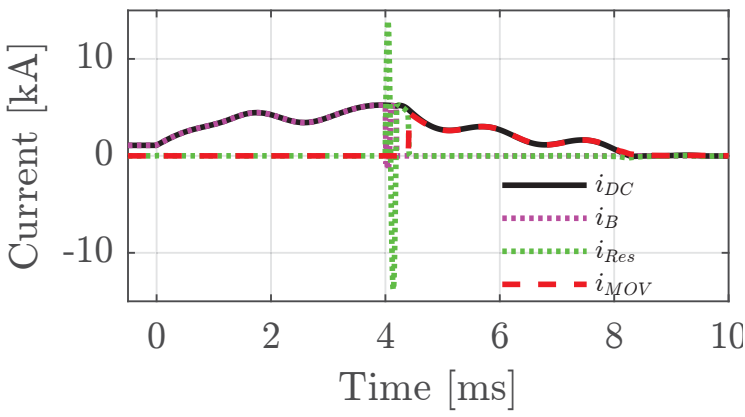

(a)

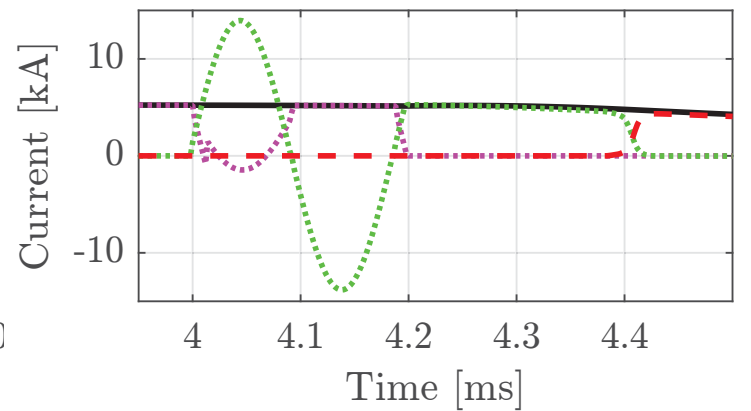

(b)

Fig. 8: (a) The DC positive pole current, the current in the mechanical interrupter, the resonant current and the surge arrester current of $B_{12 p}$ during the entire interruption process, (b) zoomed-in figure of the commutation process. 


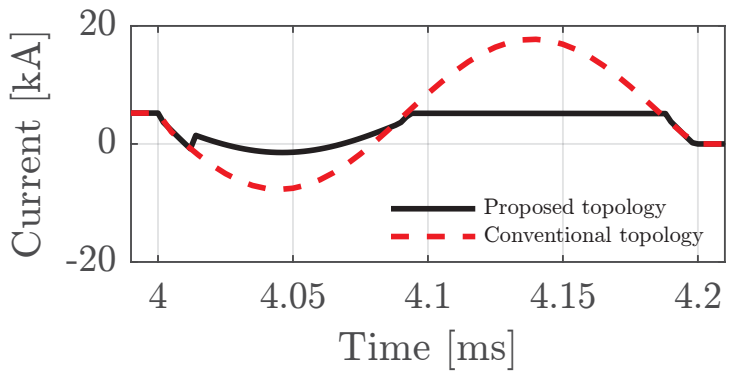

(a)

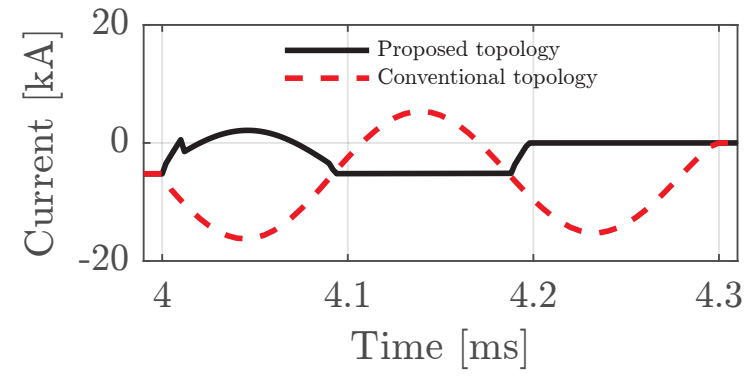

(b)

Fig. 9: Comparison of mechanical interrupter current $i_{B}$ of conventional topology and proposed topology when (a) positive DC current is interrupted, (b) negative DC current is interrupted.

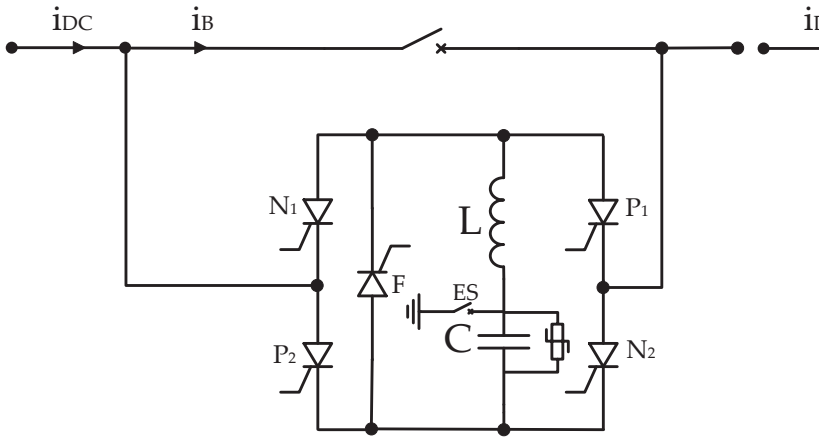

(a)

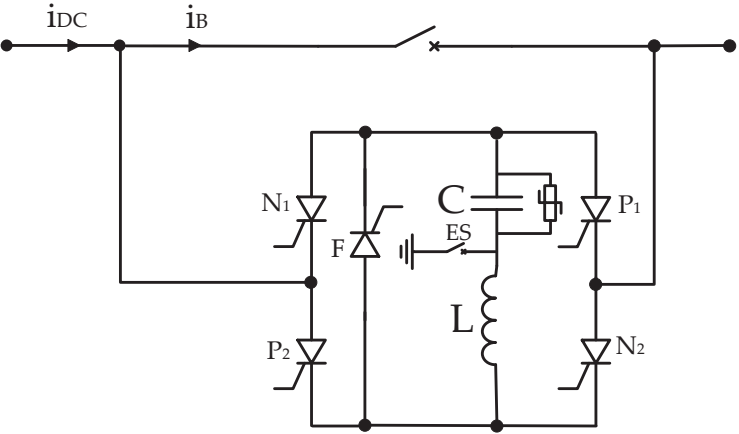

(b)

Fig. 10: (a) Positive pole topology, (b) negative pole topology.

\section{Conclusion}

The proposed improvement to the active-resonance DC circuit breaker limits internal breaker currents and favors multiple interruption attempts. Furthermore, it has the ability to inject the resonant current in both directions depending on the DC current, and the ability of reversing the polarity of the capacitor without any additional stress on the mechanical interrupter. The proposed topology thus may allow to increase circuit breaker interruption capability compared with the conventional active-resonance topology and may improve multiple reclose performance, if required.

The arc and the non-ideal thyristor behaviors may have an impact on the commutation process. Therefore, further investigations should be carried out to study the commutation behavior with the detailed models of the thyristors and the electric arc.

\section{References}

[1] Bucher M. K., Walter M. M., Pfeiffer M., Franck C. M.: Options for ground fault clearance in HVDC offshore networks, 2012 IEEE Energy Conversion Congress and Exposition (ECCE), Raleigh, NC, 2012, pp. 2880-2887.

[2] Atmadji A.: Direct Current Hybrid Breakers: A Design and its Realization, Ph.D. dissertation, Techinical University of Eindhoven, Eindhoven, The Netherlands.

[3] Callavik M., Blomberg A., Häfner J., Jacobson B.: The Hybrid HVDC Breaker: An innovation breakthrough enabling reliable HVDC grids, ABB Grid Systems, Technical paper, 2012.

[4] Häfner J., Jacobson B.: Proactive Hybrid HVDC Breakers -A key innovation for Reliable HVDC grid, Cigré Symposium, Bologna, 2011.

[5] Wang Y., Marquardt R.: Performance of a new fast switching DC-Breaker for meshed HVDC-Grids, $17^{\text {th }} \mathrm{Eu}-$ ropean Conference on Power Electronics and Applications (EPE'15 ECCE-Europe), Geneva, 2015, pp. 1-9.

[6] Krishnan J., Gueldner H., Handt K., Nielebock S.: A modular bi-directional hybrid circuit breaker for medium and high voltage DC networks, $18^{\text {th }}$ European Conference on Power Electronics and Applications (EPE'16 ECCE Europe), Karlsruhe, 2016, pp. 1-9. 
[7] Bachmann B., Mauthe G., Ruoss E., Lips H. P., Porter J., Vithayathil J.: Development of a 500kV Airblast HVDC Circuit Breaker, IEEE Transactions on Power Apparatus and Systems, Vol. PAS-104, No. 9, September 1985.

[8] Ängquist L., Norrga S., Modéer T.: A new dc breaker with reduced need for semiconductors, $18^{\text {th }}$ European Conference on Power Electronics and Applications (EPE'16 ECCE Europe), Karlsruhe, 2016, pp. 1-9.

[9] Greenwood A. N., Lee T. H.,: Theory and Application of the Commutation Principle for HVDC Circuit Breakers, in IEEE Transactions on Power Apparatus and Systems, vol. PAS-91, no. 4, pp. 1570-1574, July 1972.

[10] Pauli B., Mauthe G., Ruoss E., Ecklin G., Porter J., Vithayathil J.: Development of a High Current HVDC Circuit Breaker with Fast Fault Clearing Capability, IEEE Transactions on Power Delivery, Vol. 3, No. 4, October 1988.

[11] Bonkarev M.: Concept Analysis for High-Voltage Direct-Current Circuit Breakers for Application in a Network of HVDC Transmission, Ph.D. dissertation, Brandenburg University of Technology, Cottbus, Germany.

[12] Tahata K., Oukaili S. E., Kamei K., Yoshida D., Kono Y., Yamamoto R., Ito H.: HVDC circuit breakers for HVDC grid applications, $11^{\text {th }}$ IET International Conference on AC and DC Power Transmission, Birmingham, 2015, pp. 1-9.

[13] Hardt N., Heimbach M., Bohme H., Gentsch D.: The Dynamic Voltage/Current Characteristics of Vacuum Arcs after Breakdown at Currents in the Lower kHz-range, European Transactions on Electrical Power, Vol. 12, Issue 5, September 2002.

[14] Ahmed N., Ängquist L., Norrga S., Nee H. P.: Validation of the continuous model of the modular multilevel converter with blocking/deblocking capability, $10^{\text {th }}$ IET International Conference on AC and DC Power Transmission (ACDC 2012), Birmingham, 2012, pp. 1-6.

[15] Leterme W., Ahmed N., Beerten J., Angquist L., Van Hertem D., Norrga S.,: A new HVDC grid test system for HVDC grid dynamics and protection studies in EMT-type software, in AC and DC Power Transmission, $11^{\text {th }}$ IET International Conference on AC and DC Power Transmission, Birmingham, 2015, pp. 1-7. 